\title{
Early Results of Total Hip Arthroplasty in Osteoarthritis of Hip
}

ISSN: 2576-8875

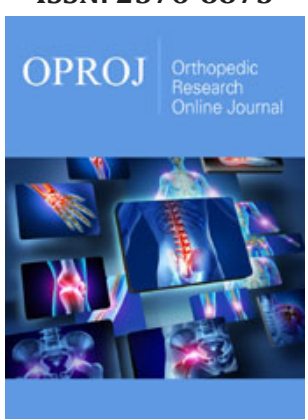

*Corresponding author: Muhammad Inam, Department of Orthopedic and Trauma Medical Teaching Institute Lady Reading, Pakistan

Submission: 沮 April 23, 2020

Published: 想April 29, 2020

Volume 7 - Issue 1

How to cite this article: Muhammad Inam, Ihsanullah, Javed Iqbal, Mian Amjad Ali, Muhammad Shabir. Early Results of Total Hip Arthroplasty in Osteoarthritis of Hip. Ortho Res Online J. 7(1). OPROJ. 000654.2020

DOI: 10.31031/OPROJ.2020.07.000654

Copyright@: Muhammad Inam, This article is distributed under the terms of the Creative Commons Attribution 4.0 International License, which permits unrestricted use and redistribution provided that the original author and source are credited.

\section{Muhammad Inam ${ }^{1 *}$, Ihsanullah ${ }^{2}$, Javed Iqbal ${ }^{3}$, Mian Amjad Ali ${ }^{1}$ and Muhammad} Shabir ${ }^{1}$

1Department of Orthopedic and Trauma Medical Teaching Institute Lady Reading, Hospital Peshawar Pakistan, Pakisthan

${ }^{2}$ Medical Officer, Hospital Daggar Bunir Khyber Pakhtoonkhwa, Pakisthan

${ }^{3}$ Medical Officer, Hospital Shabqadar Charsadda, Pakistan

\section{Abstract}

Objective: The objective of this study is to evaluate the early results of total hip arthroplasty in osteoarthritis of the hip.

Material and Method: This case series study was conducted in the Department of Orthopedic and Trauma, Medical Teaching Institute Lady Reading Hospital Peshawar from March 2017 to February 2018 on 39 consecutive patient of age 55 and above with primary osteoarthritis of the hip. In all these patient cemented arthroplasty of Surgival manufacturer was done through direct lateral approach and patients were mobilized on first post operative day. Patients were followed up on three months, six months and one year duration.

Results: A total of fifty four patients were included in the study but at final follow up only thirty nine has been seen. So we analyzed only those thirty nine patients for any complication. Out of thirty nine patients, 13(33.3\%) were female and 26(66.7\%) were male. Mean age of the patients were 63.05(Std. Deviation 4.359) with minimum 55 years and maximum 70 years. We have lost 15 patients to follow up. The remaining thirty nine has dislocation in $1(2.6 \%)$, peri prosthetic fracture in $1(2.6 \%)$ and infection in $2(5.1 \%)$ patients. Two $(5.1 \%)$ patients has severe pain and $3(7.7 \%)$ were not satisfied post operatively.

Conclusion: Total hip arthroplasty has best results in primary osteoarthritis of the hip in old age provided that the patient follows the post operative protocol for hip arthroplasty.

Keywords: Arthroplasty; Acetabulam; Activity of daily living; Hip; Osteoarthritis; Pain; Satisfaction

\section{Introduction}

Where there is osteoarthritis there is arthroplasty. Not every patient need arthroplasty in osteoarthritis but most patients will need it in some stage of life [1]. Arthroplasty is now in vogue in Pakistan for osteoarthritis of hip and knee joints [2]. Before this hip has to be fused in adult to reduce pain but the patient would then be unable to flex or extend the hip and many of them has not tolerated the procedure [3]. Fusion of the hip is a cumbersome procedure that a young adult may not cope with it and most of time it fails. When the fusion fails then pain is unbearable to the patient and avoid using the limb that causes weakness of the whole limb and may prone to fracture [4].

Fracture of acetabulam also was a big challenge for the surgeon as it may develop osteoarthritis or may developed osteonecrosis of the head of the femur [5]. Hip dysplasia in young adults has deformed hip joint with dislocation [5]. The only solution for all such conditions is joint replacement. It may be a part of the joint (hemiarthroplasty) or total joint replacement [6]. Hemiarthroplasty is not used now days as compared to total arthroplasty. Arthroplasty of hip may cement or none cemented. In most of the world the orthopedic surgeons use no cemented arthroplasty for any age but in our part of the world surgeons prefer cemented arthroplasty for old age and none cemented for younger age [7]. Sometime hybrid arthroplasty is used in young age. Still controversies exist for cemented, no cemented or hybrid arthroplasty of hip but it is the most commonly used surgery for osteoarthritis of the hip [8]. Intra operative complication of cemented arthroplasty is the bone cement syndrome which may leads to loss of life of the patient [9]. To avoid the bone cement syndrome, surgeons nowadays use the noncemented arthroplasty irrespective of age. Non 
cemented arthroplasty has higher cost rate and the manufacturer may have a role to play with the surgeons [10]. However the benefits of arthroplasty either cemented or noncemented may not be overlooked for the management of osteoarthritis of the hip; either primary or secondary osteoarthritis [5]. The objective of this study is to evaluate the early results of total hip arthroplasty in osteoarthritis of the hip.

\section{Materials and Methods}

This case series study was conducted in the Department of Orthopedic and Trauma, Medical Teaching Institute Lady Reading Hospital Peshawar from March 2017 to February 2018 on 39 consecutive patient of age 55 and above with primary osteoarthritis of the hip. In all these patient cemented arthroplasty of surgical manufacturer was done.

All those patients of either gender that have primary osteoarthritis of hip, diagnosed clinically and confirmed by radiograph of the hip taken in anteroposterior and lateral projection. Then patients were counseled about the procedure and postoperative protocol for dialy living activities. Those patients who were willing to be put in the study were included in the study with written informed consent. All the co morbid conditions were optimized and then the patients were operated.

Patient were admitted well before surgery and after optimizing the conditions of the patients and counseling for post operative care, were put on operation list on the top and either spinal or general anesthesia were given to the patient. Hip was operated with direct lateral approach and cemented arthroplasty was done. After closure, a pillow was put to the outer side of limb to avoid external rotation and hip flexion for 24 hours, and prophylactic intravenous antibiotics were given for five days. Vancomycin 2 grams and Cefoperazone+sulbactum 2 grams were given intra operatively 20 minutes before giving incision. The same antibiotics were given for first twenty four hours and then the vancomycin was stopped. Anterioposterior and lateral radiograph was taken to see the position of cup and stem. On first post operative day the patient is mobilized by the physiotherapist and walking is allowed with the help of Zimmer frame to avoid fall. The patients were instructed to sleep on operated side, use western commode in toilet, use a stick to avoid fall, use of wall mounted handles in toilets, and do not flex, abduct or adduct hip more than 900. Stitches were removed after 15 days and the wound was examined for any infection. Then the patients were followed up for three months, six months and at one year time. Patient satisfaction about movements and pain reduction is noted. Pain is noted with the visual analogue score(VAS) while patient was asked about his/her openion about satisfaction about procedure and will it recommend to fellow were also noted at final follow up. Any complication like infection, dislocation, periprosthetic loosening or fracture was noted. All the data collected with the help of a proforma was then put into the SPSS version 17 and analyzed for frequencies.

\section{Results}

A total of fifty four patients were included in the study but at final follow up only thirty nine has been seen. So we analyzed only those thirty nine patients for any complication. Out of thirty nine patients, $13(33.3 \%)$ were female and $26(66.7 \%)$ were male (Table 1).

\section{Table 1:}

\begin{tabular}{|c|c|c|c|c|c|}
\hline \multicolumn{5}{|c|}{ Gender of Patient } \\
\hline \multirow{2}{|c|}{} & Frequency & Percent & $\begin{array}{c}\text { Valid } \\
\text { Percent }\end{array}$ & $\begin{array}{c}\text { Cumulative } \\
\text { Percent }\end{array}$ \\
\hline \multirow{3}{*}{ Valid } & Female & 13 & 33.3 & 33.3 & 33.3 \\
\cline { 2 - 6 } & Male & 26 & 66.7 & 66.7 & 100.0 \\
\cline { 2 - 6 } & Total & 39 & 100.0 & 100.0 & \\
\hline
\end{tabular}

Mean age of the patients were 63.05(Std. Deviation 4.359) with minimum 55 years and maximum 70 years (Table 2).

\section{Table 2:}

\begin{tabular}{|c|c|c|}
\hline \multicolumn{2}{|c|}{ Statistics } \\
\hline \multirow{2}{*}{ Valid } & Age of the Patient \\
\hline \multirow{2}{*}{ Missing } & 39 \\
\hline & Mean & 0 \\
\cline { 2 - 3 } & Median & 63.05 \\
\hline Mode & 64.00 \\
\hline Std. Deviation & 60 \\
\hline Variance & 4.359 \\
\hline Range & 18.997 \\
\hline Minimum & 15 \\
\hline Maximum & 55 \\
\hline Sum & 70 \\
\hline
\end{tabular}

We have lost 15 patients to follow up. The remaining thirty nine has dislocation in $1(2.6 \%)$, peri prosthetic fracture in $1(2.6 \%)$ and infection in $2(5.1 \%)$ patients (Table 3$)$.

Table 3:

\begin{tabular}{|c|c|c|c|c|c|}
\hline \multicolumn{6}{|c|}{ Complications } \\
\hline & & Frequency & Percent & $\begin{array}{l}\text { Valid } \\
\text { Percent }\end{array}$ & $\begin{array}{c}\text { Cumulative } \\
\text { Percent }\end{array}$ \\
\hline \multirow{5}{*}{ Valid } & & 35 & 89.7 & 89.7 & 89.7 \\
\hline & Dislocation & 1 & 2.6 & 2.6 & 92.3 \\
\hline & Infection & 2 & 5.1 & 5.1 & 97.4 \\
\hline & $\begin{array}{c}\text { Peri } \\
\text { Prosthetic } \\
\text { Fracture }\end{array}$ & 1 & 2.6 & 2.6 & 100.0 \\
\hline & Total & 39 & 100.0 & 100.0 & \\
\hline
\end{tabular}

Table 4:

\begin{tabular}{|c|c|c|c|c|}
\hline \multicolumn{5}{|c|}{ Post Op Pain } \\
\hline & Frequency & Percent & $\begin{array}{c}\text { Valid } \\
\text { Percent }\end{array}$ & $\begin{array}{c}\text { Cumulative } \\
\text { Percent }\end{array}$ \\
\hline No Pain & 37 & 94.9 & 94.9 & 94.9 \\
\hline Sever Pain & 2 & 5.1 & 5.1 & 100.0 \\
\hline Total & 39 & 100.0 & 100.0 & \\
\hline
\end{tabular}


In the second and third follow up one patient has develop sever pain due to dislocation and peri prosthetic fracture respectively in each follow up with the frequency of 5.1\% (Table 4). In the last follow up the entire patient were pain free.

At the last follow up 92.3\% (36) patients were satisfied with the procedure and recommend it for fellow and only $7.7 \%(3)$ patients were not satisfied (Table 5). These three patient were with dislocation hip in one, infection in one and peri prosthetic fracture in one patient.

Table 5:

\begin{tabular}{|c|c|c|c|c|}
\hline \multicolumn{5}{|c|}{ Satisfaction } \\
\hline & Frequency & Percent & $\begin{array}{c}\text { Valid } \\
\text { Percent }\end{array}$ & $\begin{array}{c}\text { Cumulative } \\
\text { Percent }\end{array}$ \\
\hline Satisfied & 36 & 92.3 & 92.3 & 92.3 \\
\hline Unsatisfied & 3 & 7.7 & 7.7 & 100.0 \\
\hline Total & 39 & 100.0 & 100.0 & \\
\hline
\end{tabular}

In the first follow up one patient $(2.6 \%)$ came with dislocation that has been admitted through casualty, was prepared for elective list, open reduction was done and again the patient was counseled for post operative care. There were two cases of infection, one was found in first follow up and the second one in third follow up. In first case, it was a superficial infection and was treated with injection cefoperazone + sulbactam 2 gram intravenously for 14 days and then switched to oral Co-amoxiclav 1 gram twice daily for one month. The other case with infection was managed with debridement and same antibiotics.

In last follow up one patient has peri prosthetic fracture that occurred due to fall in bathroom. Open reduction and fixation with wire was done and patients were mobilized with help of crutches with touch weight bearing.

\section{Discussion}

Osteoarthritis $(\mathrm{OA})$ is a debilitating disease that causes severe pain of the affected jount. It is a common cause of deterioration in the movement of joint in old age populations [1]. Conservative management drug or physiotherapy in advanced stages of $\mathrm{OA}$ is of no use. With Arthroplasty patient become pain free with full movements of the joint that improves the quality of life but not prolong it [11].

Total hip arthroplasty is in vogue for primary or secondary osteoarthritis of the hip joint. However those patients who do not follow the post operative instruction may end with disaster. Pre operative planning and proper patient counseling about the post operative care make this procedure successful and almost all patients are satisfied with it [12].

In 2008 Hamel et al. [12] has done a study one 174 patients that has mean age of 75 years with $76 \%$ female and $14 \%$ male. Mean Western Ontario and McMaster Universities Osteoarthritis Index (WOMAC) score was 56 on a 100-point scale. In the last followup, no patients died, $17 \%$ had postoperative complications. There was postoperative pain in $38 \%$ patients for more than a month. Patients were able for Independent walking in round about 12 days and were able to perform activity of daily living in 49 days. In their study there was improvement of WOMAC scores by 24 points in operated patient as compare to 0.5 point improvement in non operative patients $(\mathrm{P}<.001)$.

Hafkamp et al. [13] has done a study on THA for pain relief and improvement in walking ability of the patient. In his study the average age of patients was 70 years with male of $43 \%$ and female of $57 \%$. More than $90 \%$ patients have pain relief and improvement of dialy activity in first follow up year.

Wiering et al. [14] studied 2776 with arthroplasty and showed improved functioning in $43.7 \%$ patient after surgery. He concluded that almost all patients who have done surgery were satisfied that their expectations were fulfilled for activity of daily living and pain relief which is comparable to the current study.

Gossec et al. [15] has included 1909 patients in his study in which there was OA of knee in 1130 while 779 patients has OA of the hip. Male patients were $41.9 \%$ while female were $58.1 \%$. Average age was 66.4(SD10.9) years. Joint Replacement was recommend in OA knee was in (55.6\%) while OA hip in 574(73.7\%. The recommended patients for Joint Replacement had worst pain and functional impairment that was improved to $87 \%$ post operatively. In the current study pain was improve in $90 \%$ cases Pietrzak et al. [16] studied 100 patients undergone arthroplasty. The frequency of Methicillin Sensitive Staphylococcus aureus colonization was $31.9 \%$ ( $\mathrm{n}=38$ ) in THA while no case of Methicillin Resistant Staphylococcus aureus (MRSA). Five day of oral antibiotics were given and was successful in $94.74 \%$ while the remaining needed debridement and parenteral antibiotics and was cured in two weeks.

Weiser et al. [17] in 2013 done a Retrospective cohort study Level-III on 1660 THAs. 845 (1.2\%) out of 1660 patient treated locally whith chlorohexidine has developed infection of $1.2 \%$ as compare to the remaining patient that has not been treated with chlorohexidine developed surgical site infection of $1.5 \%$. all these studies are comparable to our study in surgical site infection.

We have lost 14 patients to follow up and we do not know about the condition of those patients that what was the reason for not following the protocol. Another thing was that our follow up time was one year which needs to be evaluated further. We have limited number of patients that was studied.

\section{Conclusion}

Osteroarthritis either primary or secondary can leads to crippling pain and deteriorate the quality of life. For relief of pain and restoring activity of daily living one can offer total hip arthroplasty to the patient. It improves the quality of life but not prolong it. Careful patient selection and proper counseling for post of care can help the patient to minimize complication.

\section{References}

1. Gignac MAM, Irvin E, Cullen K, Van Eerd D, Beaton DE, et al. (2020) Men and women's occupational activities and the risk of developing 
osteoarthritis of the knee, hip, or hands: A systematic review and recommendations for future research. Arthritis Care Res (Hoboken) 72(3): 378-396.

2. Stadig S, Lascelles BDX, Nyman G, Bergh A (2019) Evaluation and comparison of pain questionnaires for clinical screening of osteoarthritis in cats. Vet Rec 185(24): 757.

3. Metcalfe D, Perry DC, Claireaux HA, Simel DL, Zogg CK, et al. (2019) Does this patient have hip osteoarthritis?: The rational clinical examination systematic review. JAMA 322(23): 2323-2333.

4. Teirlinck CH, Dorleijn DMJ, Bos PK, Rijkels-Otters JBM, Bierma-Zeinstra SMA, et al. (20190 Prognostic factors for progression of osteoarthritis of the hip: a systematic review. Arthritis Res Ther 21(1): 192.

5. Rainville J, Bono JV, Laxer EB, Kim DH, Lavelle JM, et al. (2019) Comparison of the history and physical examination for hip osteoarthritis and lumbar spinal stenosis. Spine J 19(6): 1009-1018.

6. Heerey JJ, Kemp JL, Mosler AB, Jones DM, Pizzari T, et al. (2019) What is the prevalence of hip intra-articular pathologies and osteoarthritis in active athletes with hip and groin pain compared with those without? A systematic review and meta-analysis. Sports Med 49(6): 951-972.

7. Farkas GJ, Schlink BR, Fogg LF, Foucher KC, Wimmer MA, et al. (2019) Gait asymmetries in unilateral symptomatic hip osteoarthritis and their association with radiographic severity and pain. Hip Int 29(2): 209-214

8. Lawrenson PR, Crossley KM, Vicenzino BT, Hodges PW, James G, et al. (2019) Muscle size and composition in people with articular hip pathology: a systematic review with meta-analysis. Osteoarthritis Cartilage 27(2): 181-195.

9. Ferguson RJ, Prieto-Alhambra D, Walker C, Yu D, Valderas JM, et al (2019) Validation of hiposteoarthritis diagnosis recording in the UK Clinical Practice Research Datalink. Pharmacoepidemiol Drug Saf 28(2): 187-193.
10. Manheimer E, Cheng K, Wieland LS, Shen X, Lao L, et al. (2018) Acupuncture for hip osteoarthritis. Cochrane Database Syst Rev 5: CD013010. doi: 10.1002/14651858.CD013010.

11. Tilbury C, Holtslag MJ, Tordoir RL, Leichtenberg CS, Verdegaal SH, et al. (2016) Outcome of total hip arthroplasty, but not of total knee arthroplasty, is related to the preoperative radiographic severity of osteoarthritis. A prospective cohort study of 573 patients. Acta Orthop 87(1): 67-71.

12. Hamel MB, Toth M, Legedza A, Max P (2008) Joint replacement surgery in elderly patients with severe osteoarthritis of the hip or knee; decision making, postoperative recovery, and clinical outcomes. Arch Intern Med 168(13): 1430-1440.

13. Hafkamp FJ, Lodder P, de Vries J, Gosens T, den Oudsten BL (2020) Characterizing patients' expectations in hip and knee osteoarthritis. Qual Life Res doi: 10.1007/s11136-019-02403-6.

14.Wiering B, de Boer D, Delnoij D (2018) Meeting patient expectations: patient expectations and recovery after hip or knee surgery. Musculoskelet Surg 102(3): 231-240.

15. Gossec L, Paternotte S, Maillefert JF, Combescure C, Conaghan PG, et al. (2011) The role of pain and functional impairment in the decision to recommend total joint replacement in hip and knee osteoarthritis: an international cross-sectional study of 1909 patients. Report of the OARSI-OMERACT Task Force on total joint replacement. Osteoarthritis Cartilage 19(2): 147-154.

16. Pietrzak JRT, Maharaj Z, Mokete L (2020) Prevalence of Staphylococcus aureus colonization in patients for total joint arthroplasty in South Africa. J Orthop Surg Res 15(1): 123.

17. Weiser MC, Moucha CS (2015) The current state of screening and decolonization for the prevention of Staphylococcus aureus surgical site infection after total hip and knee arthroplasty. J Bone Jt Surg 97(144): 1449-1458.

For possible submissions Click below: 